\title{
WWW.Com: A Brief Intervention to Bolster a 5th Grader's Regrouping Skills in Math
}

\author{
Matthew Waugh \\ University of British Columbia \\ Gina Harrison \\ University of Victoria
}

\begin{abstract}
This study examined the efficacy of a brief math intervention using cognitive behaviour instruction (CBI) supplemented by a mnemonic cue system for a 5th grade student with math computation and fluency difficulties. Regrouping operations in addition and subtraction were the targeted skills. Curriculum-based measurements were conducted at the end of each session to monitor the student's response to the intervention. Pre- and post-assessment with alternate forms of Key Math-Revised were also conducted. As compared to baseline performance, there was a 48\% improvement in computing regrouping problems. There was a greater effect on accuracy in computing addition than on subtraction problems requiring regrouping, based on the post-intervention assessment. The results are discussed in relation to previous intervention research incorporating CBI approaches aimed at promoting students' cognitive, metacognitive, and selfregulatory skills for proficient computation.
\end{abstract}

Essential skills required to develop mathematical proficiency include understanding concepts and operations, computing mathematical procedures accurately and efficiently, applying and formulating problems mathematically, enlisting appropriate strategies for computation, explaining and justifying a solution when solving a math problem, and perceiving mathematics as useful and practical in everyday situations (National Research Council, 2002).

A lack of automaticity and poor error detection when computing math problems that require regrouping have been commonly observed in students with math difficulties (Geary, Hamson, \& Hoard, 2000; Jordan \& Montani, 1997; Kroesbergen \& Van Luit, 2003; Swanson \& Jerman, 2006) and can impact development of skills required for mathematical proficiency. 
Since skill in computation relies upon the development of automatizing arithmetic facts and concepts (National Mathematics Advisory Panel, 2008), these skills should be learned and practiced early in elementary school. Without this early focus on developing proficiency in computation, it will likely be increasingly difficult for students to progress in their math skills at the secondary level (Steel \& Funnell, 2001).

Several error patterns have been observed from both novice and more experienced students with math-based difficulties, whose errors in regrouping can persist despite efforts made by teachers in their math instruction. Common errors include subtracting smaller numbers from larger numbers (e.g. $305-196=291$ ) regardless of position (National Research Council, 2002). Another, albeit less frequent, error type identified by Resnick (1982) occurs when a student borrows from the tens column and carries to the ones column but does not continue the procedure left of the original column for which they borrowed from (e.g., $345-186=259$ ). When computing addition problems, errors in regrouping may include a misunderstanding of the place value system, not appropriately regrouping when necessary (e.g. $305+196=4,911$ because $5+6=11$ ) or committing errors in multiple regrouping calculations (e.g. $305+196=$ 491). When error patterns persist well beyond students' introduction to regrouping into later elementary and middle school years despite teacher instruction and continued student practice, such difficulties can have an enduring impact on children's academic progress in math, particularly as they transition from one grade to the next (Steel \& Funnell, 2001).

This paper describes an intervention designed to address one student's difficulties with regrouping algorithms in computing addition and subtraction problems. Stephanie's academic profile indicated well-developed oral language and literacy skills, and no difficulties conceptually in applying math concepts to solve problems. Her computation skills were well below age expectations, however. Drawing on cognitive and metacognitive instructional models, we designed a research-based intervention to improve Stephanie's regrouping skills. Ultimately we hoped that by bolstering regrouping skills, we would be promoting her mathematical proficiency as she transitioned to middle school.

\section{Cognitive and Metacognitive Approaches to Math Intervention}

Cognitive components and skills related to math competency underpin contemporary theories and models informing math intervention research (Frensch \& Geary, 1993; Geary, 2004, 2007; Pegg, Graham, \& Bellert, 2005; Russell \& Ginsburg, 1984; Woodward, 2006). Specifically, two important cognitive mechanisms are the central executive and the phonological loop. The central executive is a parent system in the brain that controls attentional and inhibitory processes required to detect errors and performs steps in solving more complex math, such as regrouping (e.g., Frensch \& Geary, 1993; Geary, 2007). The phonological loop is a subsidiary system responsible for the articulation of such problem-solving steps and is pivotal during math reasoning tasks that require high levels of verbal processing and retaining and maintaining information concerning math concepts (Meyer, Salimpoor, Wu, Geary, \& Menon, 2009).

In their earlier development of math skills, young students rely heavily on the central executive and the phonological loop for basic numerical operations, as these brain mechanisms control the attentional and inhibitory processes to carry out procedures associated with more complex math; and as students develop their strategies in mathematics, they may become more efficient at recalling basic concepts and facts (Baddeley, 1986; Meyer et al., 2009). Moreover, 
when basic math facts become more automatized, students reduce their cognitive workloads of lower-level computation and move toward visuo-spatial relationships for more complex math (Meyer et al., 2009). For some students, the central executive may not be correctly regulating the flow of information being received, leading to difficulties with sequencing more complex math problems and with retaining and recalling basic math concepts (Geary, 2004). However, a student who has a well-developed phonological loop may exhibit strengths with oral comprehension (i.e., verbal directions and recall of information through verbal means). For students who excel in oral comprehension, but who struggle in learning and remembering the sequences of steps in computation, self-regulatory strategies that emphasize verbal teacher and student self-instruction have been found to be effective in promoting skills development (e.g., Dignath \& Büttner, 2008). In their meta-analysis examining the impact of intervention programs to develop students' cognitive and metacognitive strategy use and self-regulatory skills, Dignath \& Büttner (2008) reported the greatest effect sizes for interventions aimed at math rather than reading or writing, particularly among elementary age students.

Cognitive-based instruction (CBI), which combines cognitive and metacognitive strategy use, appears well suited for those students who exhibit oral language strengths, as overt verbalizations to the self and to the teacher are key components of the intervention. Many students with math-based learning difficulties experience problems with inaccurate or underdeveloped knowledge of math concepts, an inadequate use of recall strategies, and problems with math-fact retrieval, ultimately leading to a high cognitive load and reduced working memory resources for performing more advanced mathematical tasks (Woodward, 2006). Students with well-developed language skills (i.e., with a well-developed phonological loop) may be able to compensate for their difficulty with regulating the flow of information during math computation. A CBI approach may therefore improve a student's metacognitive abilities to accurately apply basic math concepts, which can reduce cognitive load on lower-level mathematics, thereby freeing up valuable working memory resources and facilitating more advanced arithmetic problem solving (Pegg et al., 2005). Vaughn, Bos, and Weaver (2012) described several instructional strategies, including CBI, for improving the performance of students struggling with math. This instructional strategy has been used to improve math problem solving (Montague, 1992) because it "focuses on teaching young students cognitive and metacognitive processes, strategies, or mental activities to facilitate learning and improve performance" (p. 285). One effective and empirically validated approach to helping students become more selfregulatory is the Self-Regulated Strategy Development (SRSD) model (Harris \& Graham, 1992). First used to target and develop writing skills, the SRSD model has also targeted reading (e.g., Johnson, Graham, \& Harris, 1997) and to a lesser extent math (e.g., Case, Harris, \& Graham, 1992). This approach facilitates student mastery of higher-level cognitive processes involved in specific tasks through the application of meta-reflective and self-regulatory skills that are embedded within instruction (see Harris, Graham, Mason, \& Saddler, 2002). SRSD can be operationalized using a six-step process including: (a) student and teacher assessment of student knowledge of a particular subject and identifying skills the student needs for a given task, (b) student and teacher co-construction of strategies and identifying the benefits of using these strategies for the task, (c) teacher or peer modeling of strategies to perform the task, (d) student memorization of the strategy, (e) teacher or peer support being provided, and (f) student comprehension leading to independent performance and ultimate fading out of tools previously implemented to acquire strategies (e.g., fading mnemonics and other cuing systems). 
Such cognitive and metacognitive instruction can have positive outcomes that generalize across academic domains (Rathvon, 2008). Intervention research has indicated that direct instruction and CBI has had the greatest effects for students with learning disabilities (Swanson, 2001) and can enhance the metacognitive and self-regulatory strategies among students experiencing difficulties with information recall and students who have various types of learning difficulties (e.g., Case et al., 1992; Chung \& Tam, 2005; Coughlin \& Montague, 2004; Harris et al., 2002; Johnson et al., 1997; Montague, 1997; Montague, Enders, \& Dietz, 2011; Saddler, 2006; Tournaki, 2003). Within the context of math-based learning difficulties, CBI aims to enhance the skill set of students so that when presented with a math problem, the student can decode and analyze the text, generate a mental representation, select an appropriate procedure as a means to a solution, and check over the answer obtained in relation to the problem given (Pape $\&$ Smith, 2002). These components form the foundation of mathematical competency and proficiency; but for many students who struggle with any number of mathematical concepts, the metacognitive reflection and strategic repertoire to perform an array of mathematical algorithms may still be developing (Kuhn, 1999). CBI, therefore, may help to remediate math difficulties, especially if the student has oral language comprehension strengths. CBI emphasizes overt selfinstruction (via self-talk) which "provides the necessary cognitive and metacognitive tools needed for higher order thinking and comprehension tasks" (Montague \& Dietz, 2009, p. 287).

\section{Intervention Purpose}

The math concept of regrouping was specifically targeted as it represented Stephanie's fundamental struggle with more complex math. The intervention presented in this paper, and cited by Vaughn et al. (2012) in their chapter concerning the assessment and teaching approaches for students with math learning difficulties, is a CBI strategy similar to the SRSD model developed by Harris and Graham (1992). The CBI strategy was designed specifically for and aimed at enhancing an elementary grade student's metacognitive and self-regulatory behaviour after the student persistently made regrouping errors and displayed other concomitant mathbased learning difficulties. This intervention seems well suited for mathematical calculations requiring regrouping, given the multiple steps needed to compute problems. We expected that by capitalizing on the student's oral language strengths through CBI, which has a strong emphasis on verbalizations and self-talk, we would ameliorate the student's self-regulation and recall of appropriate solutions to math problems requiring regrouping.

\section{Intervention Method}

\section{Participant}

Stephanie (pseudonym used) was referred by her parents and teachers to a universitybased tutoring and intervention program after demonstrating significant math-based learning difficulties compared to her same-aged peers. The first author is a certified teacher and graduate student in special education who worked under the supervision of the second author. Stephanie was 11 years old and in Grade 5 at the time of the intervention. The Woodcock-Johnson Tests of Achievement, Third Edition (WJ-III; Woodcock, McGrew, \& Mather, 2001) was administered to gain information on her overall academic skills compared to other students her age. The results of the assessment confirmed her struggles in mathematics (see Table 1), with her overall math 
score below average due specifically to problems in math computation (i.e., Calculation) and math fluency. Importantly, Stephanie's understanding and application of math concepts was assessed within the average range for her age (i.e., Applied Problems). Reading and written language skills were also assessed within age expectations, with oral language scores above average for her age, indicating an area of normative and relative strength within her learning profile. Stephanie's pattern of strength in oral language, along with higher scores (within the average range) on the Applied Problems subtest, a measure of her understanding and application of math concepts, is consistent with research on the unique aspects of mathematical cognition. In their large-scale study with over 900 third-graders, Fuchs et al. (2008) reported that specific problems with computation were associated with oral language strengths, whereas problemsolving difficulties were associated with language-based difficulties as well as with race and poverty.

\section{Table 1}

Standard Scores and Percentile Ranks Achieved on the WJ-III

\begin{tabular}{lcc}
\hline Subtest & Standard Score & Percentile Rank \\
\hline Broad Reading & $\mathbf{9 3}(\mathbf{9 2 - 9 5 )}$ & 33 \\
Letter/Word Identification & $97(94-99)$ & 41 \\
Reading Fluency & $93(91-95)$ & 31 \\
Passage Comprehension & $\mathbf{9 2 ( 8 9 - 9 6 )}$ & 31 \\
Broad Written Language & $\mathbf{9 6}(\mathbf{9 3 - 9 9 )}$ & 39 \\
Spelling & $95(92-98)$ & 37 \\
Writing Fluency & $86(81-91)$ & 17 \\
Writing Samples & $123(112-135)$ & 94 \\
Broad Math & $\mathbf{8 4}(\mathbf{8 1 - 8 6 )}$ & $\mathbf{1 4}$ \\
Calculation & $78(74-83)$ & 8 \\
Math Fluency & $68(65-71)$ & 2 \\
Applied Problems & $93(89-96)$ & 31 \\
Oral Language & $106(102-111)$ & 66 \\
Story Recall & $113(106-120)$ & 81 \\
Understanding Directions & $102(97-107)$ & 55 \\
Story Recall-Delayed & $123(115-132)$ & 94 \\
\hline
\end{tabular}

Note. Standard scores have a mean of 100 , and a standard deviation of 15 . Bracketed values represent scores at the $68 \%$ confidence interval.

Follow-up assessment was conducted with Form A of the Canadian Edition of Key Math Revised (KM-R) Diagnostic Assessment (Connolly, 1991) to gain further insight into Stephanie's math-based learning difficulties (see Table 2). The results of the KM-R indicated that Stephanie was experiencing particular difficulties with basic math computation (e.g., attention to computation sign, persistent carrying and borrowing errors), especially as it related 
to the math concept of regrouping. The error patterns discussed previously represent the kind of errors Stephanie persistently made but accurately detected post-assessment. For example, Stephanie would deduct the smaller number from the larger number regardless of its position-a common regrouping error for elementary students first exposed to the concept, but not as common for students of Stephanie's age (National Research Council, 2002). Interestingly, Stephanie articulated an understanding of regrouping when she accurately described the concepts following the initial pre-intervention assessments with the WJ-III and KM-R and was able to detect and describe the nature of her calculation errors from her math workbooks she had completed at school. Based on pre-intervention assessments, Stephanie therefore appeared to have a good grasp of the concept of regrouping, but was experiencing difficulties recalling and using the correct algorithm when computing math problems.

Table 2

Area Standard Scores, Subtest Scaled Scores, and Percentile Ranks Achieved on the KM-R Pre-Intervention

\begin{tabular}{lccc}
\hline Subtest & Standard Score & Scaled Score & Percentile Rank \\
\hline Basic Concepts & $\mathbf{8 0}$ & 5 & $\mathbf{9}$ \\
Numeration & & 9 & 6 \\
Rational Numbers & & 7 & 42 \\
Geometry & $\mathbf{6 9}$ & & 19 \\
Operations & & 3 & $\mathbf{2}$ \\
Addition & 5 & 1 \\
Subtraction & 5 & 6 \\
Multiplication & 6 & 6 \\
Division & 6 & 12 \\
Mental Computation & & 6 & 12 \\
\hline
\end{tabular}

Note. Standard scores based on a mean of 100, standard deviation of 15 . Scaled scores have a mean of 10 , standard deviation of 3 .

The interventionist and Stephanie reviewed her school math workbooks, providing her an opportunity to review and correct her calculation errors. As noted, Stephanie described the regrouping concept accurately and correctly assessed the procedural errors she made and how they could be corrected. However, when Stephanie was given a new set of problems requiring regrouping to calculate, she again struggled to adhere to the regrouping rules she appropriately articulated verbally. It was determined by the interventionist that Stephanie had a conceptual understanding of the regrouping concept, but performing the calculations while simultaneously applying the correct solution was causing her difficulty. To support the development of Stephanie's regrouping skills in math, a brief math intervention was designed to provide her a strategy to capitalize on her strong oral language skills through a CBI approach leading to improved regulation of math steps and error detection during computation. Drawing upon CBI research (Chung \& Tam, 2005; Coughlin \& Montague, 2004; Montague, 1997; Montague et al., 2011; Saddler, 2006; Tournaki, 2003), the first author, the interventionist, created a mnemonic 
based on Leon and Pepe's (1983) five-phase model for supporting arithmetic skill development in students with learning difficulties. The five phases included: (a) modeling, (b) student and teacher co-participation, (c) student demonstration, (d) fading overt self-instruction, and (e) feedback. These phases, along with the inclusion of a mnemonic, are consistent with the process commonly followed for the SRSD approach described earlier (e.g., student and teacher coconstruction of strategies and strategy benefit, teacher modeling, student memorization, teacher support provided, student independence in strategy use with fading out of cues). The present approach therefore represented a hybrid of Leon and Pepe's (1983) and Harris and Graham's (1992) models.

\section{The WWW.Com Approach}

The WWW.Com intervention was developed to draw on Stephanie's well-developed oral language skills, allowing for overt student self-instruction and monitoring to improve selfregulatory and self-monitoring skills for computation. Moreover, this intervention was developed to support the student in developing proficiency in computing addition and subtraction problems that require regrouping. In a meta-analysis on the effective instructional components of math interventions for students with learning disabilities, Gersten et al. (2009) found that the most effective instructional components included heuristics (represented by the mnemonic in the present study) with an explicit instructional approach (such as through CBI). Given the ubiquitous nature of the internet in students' lives, the mnemonic that was developed (see Figure 1) had particular relevance and resonance with the student and was therefore considered to serve as a powerful cue in recalling the heuristics involved in solving computation problems. Mnemonics can aid in self-instruction, solidify newly acquired material, and improve retention and performance across academic subjects including mathematics (Mastropieri, 1991; Mastropieri \& Scruggs, 1992; Scruggs \& Mastropieri, 1990, 2000; Wolgemuth, Cobb, \& Alwell, 2008).

\section{WWW.Com}

What is this problem asking me to do?

What numbers do I line up?

Watch for when carrying and borrowing is needed.

Compute. Solve the problem and check over my answer.

Figure 1. Mnemonic Developed by the Interventionist.

Consistent with the empirical evidence related to the CBI approach (Chung \& Tam, 2005; Coughlin \& Montague, 2004; Leon \& Pepe, 1983; Montague, 1997; Montague et al., 2011; Saddler, 2006; Tournaki, 2003), the WWW.Com intervention was designed to target Stephanie's self-regulation by focusing on her strengths in oral communication and following a five-phase 
CBI process whereby the interventionist (a) modelled the use of the mnemonic and the steps involved in solving a computation problem, (b) co-participated with Stephanie through regrouping calculations as she approached problems, (c) provided Stephanie opportunities to independently demonstrate the strategy, while closely monitoring her performance and providing feedback as necessary, (d) supported Stephanie to become more efficient to fade out her verbalized self-instruction and phasing in an internalized process, and (e) reinforced her correct sequencing as she self-instructed through the regrouping procedure. Additionally, this intervention matched the math vocabulary of "carrying" and "borrowing" used in her classroom to avoid confusion and to help promote transfer of skills to the classroom context, despite the fact that such terms may be conceptually misleading (Van de Walle, 2004). Stephanie completed the following steps in each phase of the intervention to perform each regrouping computation:

1. What is this problem asking me to do? Stephanie verbally self-instructed by asking herself what information would be important to know in each calculation problem (e.g., Am I adding? Am I subtracting?), highlighting and extracting numerical information from each math problem.

2. What numbers do I line up? Stephanie would verbally ask herself what numbers should be aligned based on the place value of the numbers and the need to add or subtract and would then perform the step by correctly aligning the numbers.

3. Watch for when carrying and borrowing is needed. Stephanie verbally cued herself of the potential need to regroup. This question supported the first step of the mnemonic by allowing the student the opportunity to self-monitor throughout a math problem for the potential need to carry (i.e., Will I need to carry because it is an addition problem?) or borrow (i.e., Will I need to borrow because it is a subtraction problem?).

4. Compute. Solve the problem and check over my answer. Once Stephanie self-instructed through each step, she would calculate the problem and then repeat the mnemonic steps to check for errors. Here, Stephanie would perform the calculation, read aloud Step 4, and then verbalize each step again.

\section{Materials and Resources}

A laminated WWW.Com mnemonic cue card was provided at the beginning of each session, along with whiteboards and manipulatives for regrouping instruction. In addition, instructional materials were familiar to Stephanie and were consistent with the materials used in the classroom during math instruction. These materials represented the instructional tools embedded within the intervention design across every session. Each session concluded with the administration of a math curriculum-based measurement (CBM). CBMs consisted of twenty double- and triple-digit addition and subtraction problems that required regrouping with the purpose of measuring and tracking Stephanie's regrouping progress. These problems were developed by the interventionist and were matched to similar math problems she was receiving in school. 


\section{Description of Session Procedures}

Sessions were approximately 45-60 minutes in length over a total of six sessions during a four-week period, which included 10-15 minutes at the end of each session to conduct the CBM. The first math CBM was administered to establish the baseline score and was followed by an introduction to the mnemonic and its role in the intervention. The session began with the interventionist verbally self-instructing each step of the WWW.Com mnemonic to complete double- and triple-digit math problems that required regrouping (modeling). Following several demonstrations, the interventionist invited Stephanie to work together to complete three word problems requiring regrouping utilizing the mnemonic (co-participation). This component expanded from the previous modeling by prompting Stephanie to explain her approach and the process she was using with the provision of corrective feedback as needed. The interventionist and Stephanie began working together at the start of the second session, progressing toward independent, self-instruction (student demonstration) to complete each step of the mnemonic. By the third session, Stephanie reduced her overt-self instruction and increased silent self-instruction (fading overt self-instruction) with WWW.Com still being used as a reference to complete regrouping problems. Sessions four, five, and six represented the shift to independent strategy use. For each of the sessions, Stephanie was presented regrouping problems to compute and was encouraged to engage in covert self-instruction, independently working through the steps as presented in the mnemonic and applying the regrouping algorithm. The interventionist gradually faded out correction and reinforcement as Stephanie moved toward accuracy and independence by session six. Each session concluded with the administration of the math CBM (described in more detail below) and a discussion with Stephanie about her progress (feedback).

\section{Student Response to Intervention}

\section{Ongoing Progress Monitoring}

Assessment of student progress included chartings of each administered math CBM and session observations of Stephanie's math performance documented through interventionist journaling and reflections. All CBMs were displayed on a 21.6- by $27.9-\mathrm{cm}$ sheet of paper, consisting of twenty double- and triple-digit addition and subtraction problems that required regrouping. Each $\mathrm{CBM}$ required the same degree of regrouping with the same number of one to three regrouping steps occurring for each item. The content of each CBM was also reviewed by the interventionist to verify that no problem appeared twice on the same CBM or appeared again on successive assessments. Scoring was based on the number of correct digits in the solution to the problem, as recommended by Hosp, Hosp, and Howell (2007). A correct digit (CD) is any digit that is correctly placed in the appropriate ones, tens, or hundreds column. For example, one math problem on the CBM administered after the first session required Stephanie to calculate $485+446$ which she answered by writing 821 . The digit in the ones column was correctly identified; however, Stephanie did not carry into the tens column, which led to her incorrectly place a 2 in the tens column. This error was repeated for the hundreds column. Therefore, the interventionist awarded one digit out of three that were possible. The CD for this problem was then added to all other CDs on that session's CBM to generate a composite score for that session's CBM. Each CBM allows for 50 possible correct digits. In contrast to scores based on the number of correct problems, $\mathrm{CD}$ scores provide a more sensitive metric of change in 
performance when used to monitor response to an intervention (Hosp et al., 2007). Although CBMs are usually timed, we administered untimed CBMs to allow Stephanie the opportunity to complete each step of the mnemonic. Accuracy rather than fluency in computation was therefore assessed over time. To validate intervention observations and CBM change in scores across sessions, the alternate Form B of KM-R was re-administered at post-intervention.

\section{Student Outcomes}

Stephanie correctly identified 23 of the 50 possible digits at baseline (Figure 2), with an immediate improvement in CDs on the second CBM at the end of the first session (30/50). In total, there was an improvement of $24 \mathrm{CDs}$ from baseline to the final session, with the largest CD improvement observed between baseline and the fifth session. Total CDs for addition problems had a modest increase with a $14.3 \%$ improvement between baseline and the final session. Total CDs for subtraction problems from baseline to the final session increased by $72.5 \%$ with a ceiling of $79.2 \%$ from baseline to session five. Stephanie consistently produced at least $80 \%$ of the total digits for sessions four to six with an overall increase of $75 \%$ from baseline established in the first session.

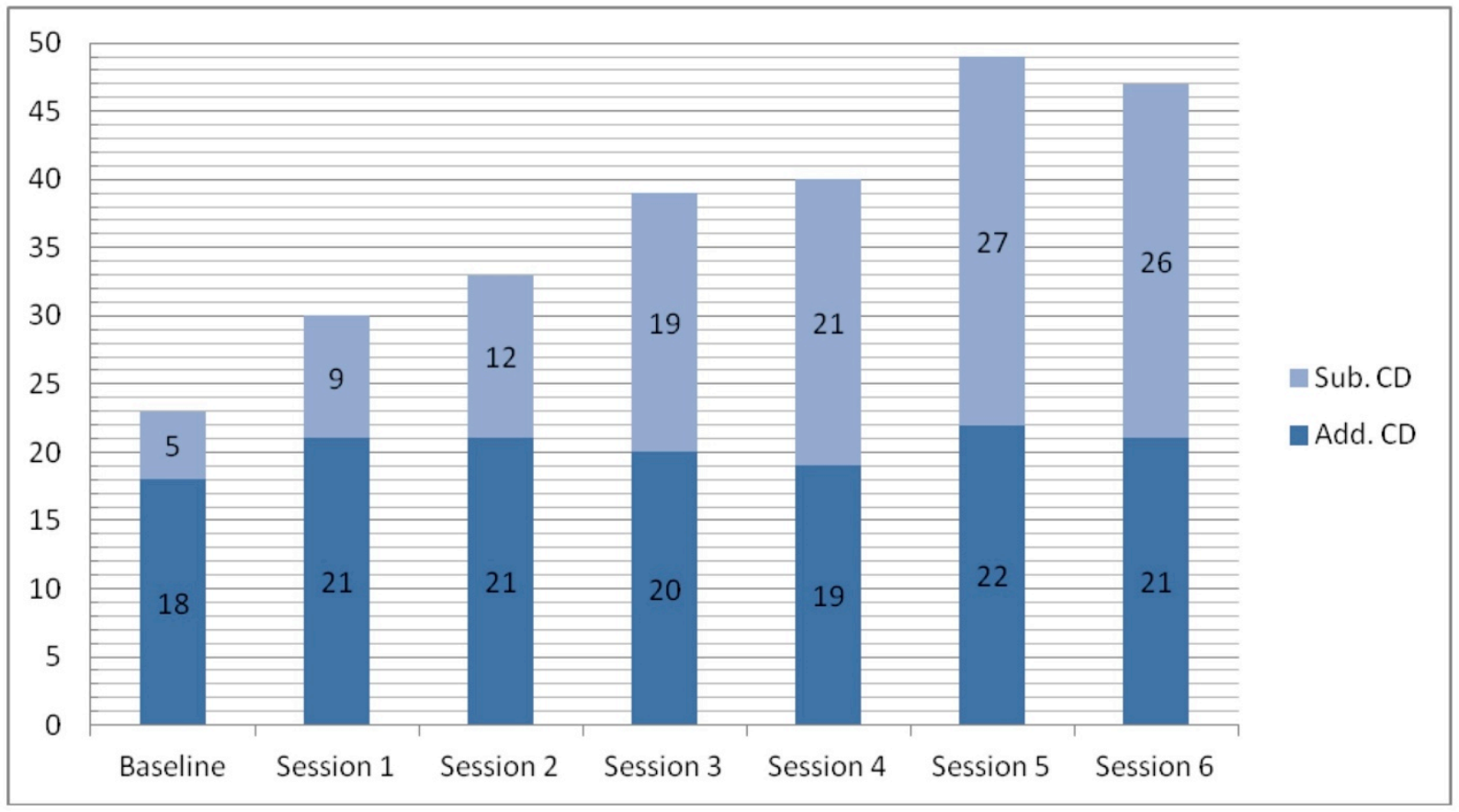

Figure 2. Intervention Results on CBM Regrouping Problems. Sub. CD = Total correct digits for subtraction problems from each session's CBM; Add. CD = Total correct digits for addition problems from each session's CBM.

Stephanie's improvement was due mainly to the correct production of digits in subtraction problems requiring regrouping, although immediate success was observed in her ability to solve addition regrouping problems with greater accuracy. With a baseline of $68 \%$ for addition problems, she increased her scores and averaged $90 \%$ for the remaining sessions of the 
intervention. This degree of improvement is compelling considering the brevity of the intervention. Overall, Stephanie correctly identified $46 \%$ of the digits on the first administered CBM. Her improvement from baseline to the end of the intervention was $48 \%$, with a ceiling of $52 \%$ between baseline and session five. Figure 3 depicts the improvement rate based on percentage of CDs produced between baseline and intervention sessions.

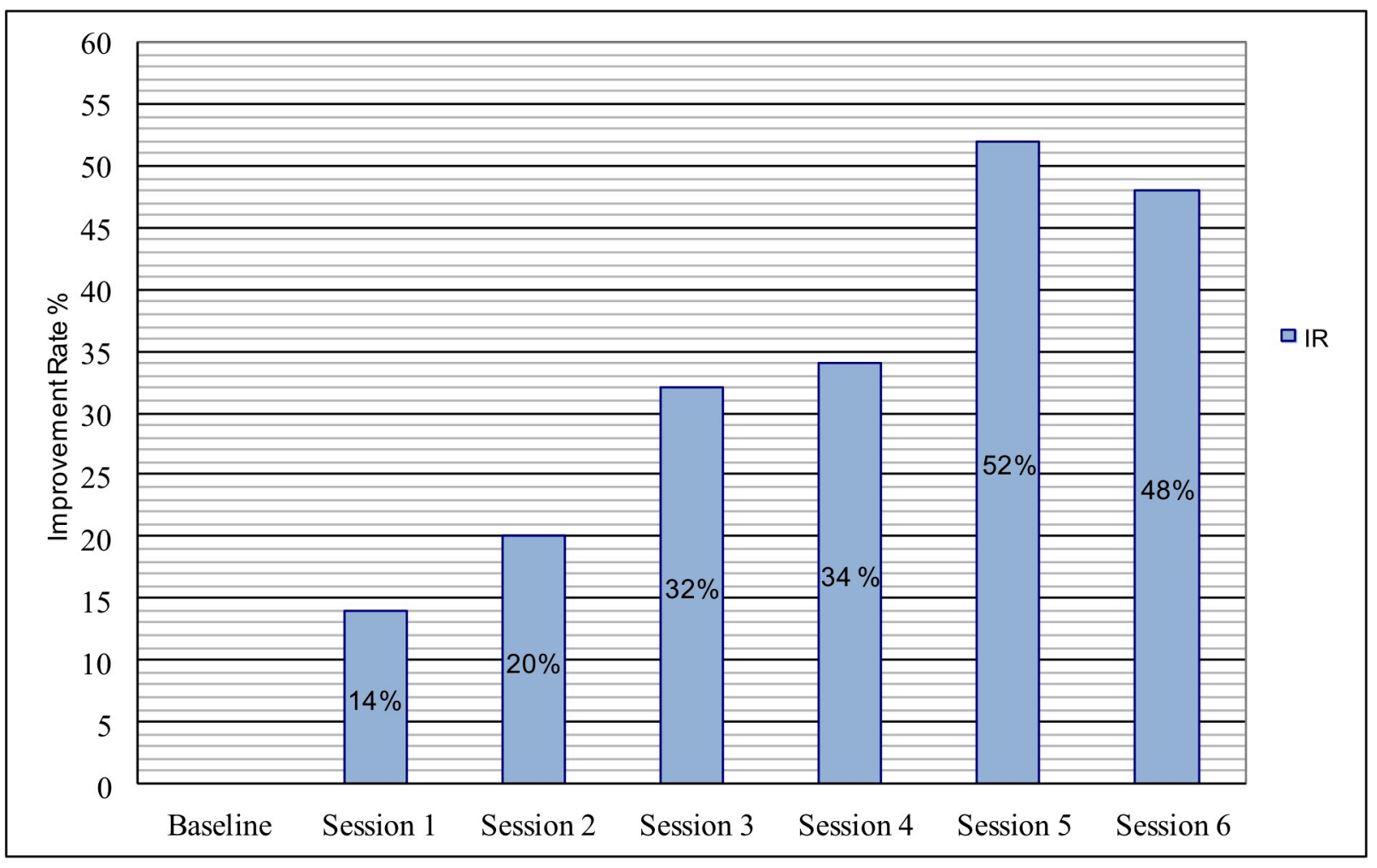

Figure 3. Improvement Rate from CBM Baseline. IR = Total improvement rate percentage for each session from baseline (percentage of correct digits for each session minus the percentage of correct digits obtained at baseline).

Select subtests from the alternate Form B of the KM-R were administered postintervention approximately four weeks following the initial administration (Table 3). Stephanie improved upon her pre-intervention assessment by achieving within the 42nd, 12th, and 30th percentile on the addition, subtraction, and mental computation subtests, respectively. Though her percentile score increased, scores on the subtraction subtest still indicated a rather significant deficit for Stephanie. It should be noted that the WWW.Com mnemonic was not provided during final assessment of the KM-R (unlike during the administration of the CBMs) to adhere to standardization, and so that the interventionist could observe transfer effects. The results may therefore be associated with the absence of the cueing system. Nonetheless, Stephanie did improve her math performance in each math content area as indicated by her post-intervention overall performance (reflected in a standard score of 79). The score falls outside the confidence interval achieved pre-intervention, making the difference meaningful and less attributable to measurement error. 
Table 3

Pre- and Post-Intervention Score Comparison of the KM-R

\begin{tabular}{lcccc}
\hline Operation & \multicolumn{2}{c}{ Pre-Test } & \multicolumn{2}{c}{ Post-Test } \\
& $\begin{array}{c}\text { Standard } \\
\text { Score }\end{array}$ & $\begin{array}{c}\text { Percentile } \\
\text { Rank }\end{array}$ & $\begin{array}{c}\text { Standard } \\
\text { Score }\end{array}$ & $\begin{array}{c}\text { Percentile } \\
\text { Rank }\end{array}$ \\
\hline Overall (Std. Dev.) & $\mathbf{6 9}(61-77)$ & $\mathbf{2}$ & $\mathbf{7 9}(71-87)$ & $\mathbf{8}$ \\
Addition & 3 & 1 & 9 & 42 \\
Subtraction & 5 & 6 & 6 & 12 \\
\hline
\end{tabular}

Note. Standard scores based on a mean of 100 , standard deviation of 15 . Scaled scores with a mean of 10 , standard deviation of 3 . Standard deviation is based on the $90 \%$ confidence interval.

\section{Discussion}

The WWW.Com intervention was designed as a CBI approach to teach regrouping in computation to Stephanie, who is struggling in math computation and fluency but has a good understanding of math concepts and applications, including a good conceptual grasp of regrouping. Stephanie's response to the intervention was immediate and positive as indicated by the increase in CDs on each session's CBM and by post-intervention performance on the KM-R. This intervention was informed by research on the relation between cognitive mechanisms supporting self-regulation and mathematics disabilities (Frensch \& Geary, 1993; Geary, 2004, 2007; Russell \& Ginsburg, 1984; Meyer et al., 2009). Students who frequently commit procedural errors on multi-step arithmetic problems, like Stephanie, may be affected by poor monitoring skills associated with the central executive (Geary, 2004). For instance, a student who correctly verbalizes the arithmetic rules for regrouping but then incorrectly applies those rules may have a well-developed phonological loop but experience difficulty regulating the flow of information while performing calculations. Similar behaviours exhibited by Stephanie were observed by the interventionist during the present intervention.

We hypothesized that a CBI approach, which capitalized on Stephanie's strong oral language skills by emphasizing verbal instruction, would effectively compensate for Stephanie's poor self-regulation and error detection when computing problems. Theoretically, Stephanie's difficulty in maintaining mental representations in working memory while simultaneously engaged in the process of regrouping (Geary, Hoard, Byrd-Craven, \& DeSoto, 2004) could have been targeted with this CBI approach, which helped to regulate the flow of information - a task given to the central executive (Baddeley, 1986, 2000). Similar to the SRSD models used elsewhere and in other content areas (Case, Harris, \& Graham, 1992; Harris \& Graham, 1992; Johnson et al., 1997), this CBI approach helped to facilitate Stephanie's mastery of higher-level mathematics by creating a cueing device that served as a regulatory tool and compensated for poor central executive functioning in error detection and maintaining mental representations in working memory.

The CBI approach with an embedded mnemonic may allow for phonological loop strengths to compensate for poor regulation stemming from the central executive. Further 
research will be necessary to better understand the differences in academic outcomes using CBI, comparing students who appropriately identify math concepts verbally but struggle in their application when computing to students with more generalized math difficulties (i.e., across computation and problem solving). While we have provided a detailed description of one student's response to this intervention, future research conducted with small groups of students (e.g., students receiving learning assistance in math) within a multiple baseline design would be informative. Such research would provide further insight into the efficacy (and ecological validity) of this approach within the context of special education, where learning support is typically delivered to groups of students. We also did not examine the transfer of the skills Stephanie acquired to her performance in math at school. The brevity of the intervention may limit the maintenance and transfer of the skills Stephanie has learned. Likewise, while Stephanie's skills for regrouping in addition improved, based on the post-intervention assessment with the KM-R, notable improvements in her regrouping skills for subtraction were not evident. We attributed this lack of improvement to the withdrawal of the cue card during this standardized assessment. However, it is likely that she required further practice with the subtraction regrouping algorithms to consolidate the steps. With more intervention sessions, it is possible that improvements would have been evident across both operations.

Most notably, this intervention adds to empirical research findings that indicate academic effectiveness from the use of a CBI approach (Chung \& Tam, 2005; Coughlin \& Montague, 2004; Harris \& Graham, 1992; Johnson et al., 1997; Leon \& Pepe, 1983; Montague, 1997; Montague et al., 2011; Saddler, 2006; Tournaki, 2003), with the present WWW.Com intervention results similar to the outcomes reported in other cognitive-based interventions specifically targeting students with math difficulties (e.g., Case et al., 1992). It is challenging for special educators to find the time to research effective interventions for students. We hope that the intervention presented here provides insight into one approach that may be effective for other students with similar learning profiles to Stephanie in bolstering their regrouping skills.

\section{References}

Baddeley. A. D. (1986). Working memory. Oxford, UK: Oxford University Press.

Baddeley, A. D. (2000). Short-term and working memory. In E. Tulving \& F. I. M. Craik (Eds.), The Oxford handbook of memory (pp. 77-92). New York, NY: Oxford University Press.

Case, L., Harris, K. R., \& Graham, S. (1992). Improving the mathematical problem-solving skills of students with learning disabilities: Self-regulated strategy development. Journal of Special Education, 26, 119. doi:10.1177/002246699202600101

Chung K. K. H., \& Tam, Y. H. (2005). Effects of cognitive-based instruction on mathematical problem solving by learners with mild intellectual disabilities. Journal of Intellectual and Developmental Disability, 30, 207-216. doi:10.1080/13668250500349409

Connolly, A. J. (1991). KeyMath-Revised: A Diagnostic Inventory of Essential Mathematics. Toronto, ON: PsyCan Corporation.

Coughlin, J., \& Montague, M. (2004). The effects of cognitive strategy instruction on the mathematical problem solving of adolescents with spina bifida. Journal of Special Education, 45, 171-183. doi:10.1177/0022466910363913

Dignath, C., \& Büttner, G. (2008). Components of fostering self-regulated learning among students: A metaanalysis on intervention studies at primary and secondary school level. Metacognition and Learning, 3, 231-264. doi:10.1007/s11409-008-9029-x 
Frensch, P. A., \& Geary, D. C. (1993). Effects of practice on component processes in complex mental addition. Journal of Experimental Psychology: Learning, Memory, and Cognition, 19, 433-456. doi:10.1037/0278-7393.19.2.433

Fuchs, L. S., Fuchs, D., Stueburg, K., Fletcher, J. M., Hamlet, C. L., \& Lambert, W. (2008). Problem solving and computational skills: Are they shared or distinct aspects of mathematical cognition? Journal of Educational Psychology, 100, 30-47. doi: 10.1037/0022-0663.100.1.30

Geary, D. C. (2004). Mathematics and learning disabilities. Journal of Learning Disabilities, 37, 4-15. doi:10.1177/00222194040370010201

Geary, D. C. (2007). An evolutionary perspective on learning disability in mathematics. Developmental Neuropsychology, 32, 471-519. doi:10.1080/87565640701360924

Geary, D. C., Hamson, C. O., \& Hoard, M. K. (2000). Numerical and arithmetical cognition: A longitudinal study of process and concept deficits in children with learning disabilities. Journal of Experimental Child Psychology, 77, 236-263. doi:10.1006/jecp.2000.2561

Geary, D. C., Hoard, M. K., Byrd-Craven, J., \& Desoto, M. (2004). Strategy choices in simple and complex addition: Contributions of working memory and counting knowledge for children with mathematical disability. Journal of Experimental Child Psychology, 88, 121-151.

Gersten, R., Chard, D. J., Jayanthi, M., Baker, S. K., Morphy, P., \& Flojo, J. (2009). Mathematics instruction for students with learning disabilities: A meta-analysis of instructional components. Review of Educational Research, 79, 1202-1242. doi:10.3102/0034654309334431

Harris, K. R., \& Graham, S. (1992). Self-regulated strategy development: A part of the writing process. In M. Pressley, K. R. Harris, \& J. T. Guthrie (Eds.), Promoting academic competence and literacy in school (pp. 277-309). New York, NY: Academic Press.

Harris, K. R., Graham, S., Mason, L. H., \& Saddler, B. (2002). Developing self-regulated writers. Theory Into Practice, 41, 110-115. Retrieved from http://www.jstor.org/stable/1477462

Hosp, M. K., Hosp, J. L., \& Howell, K. W. (2007). The ABCs of CBM: A practical guide to curriculum-based measurement. Practical Intervention in the Schools Series. New York, NY: Guilford Press

Johnson, L. A., Graham, S., \& Harris, K. R. (1997). The effects of goal setting and self- instruction on learning a reading comprehension strategy: A study of students with learning disabilities. Journal of Learning Disabilities, 30, 80-91. doi:10.1177/002221949703000107

Jordan, N., \& Montani, T. (1997). Cognitive arithmetic and problem solving: A comparison of children with specific and general mathematics difficulties. Journal of Learning Disabilities, 30, 624-634. doi:10.1177/002221949703000606

Kroesbergen, E. H., \& Van Luit, J. E. H. (2003). Mathematics interventions for children with special educational needs: A meta-analysis. Remedial and Special Education, 24, 97-114. doi: $10.1177 / 07419325030240020501$

Kuhn, D. (1999). Metacognitive development. In L. Balter \& C. S. Tamis-LeMonda (Eds.), Child psychology: A handbook of contemporary issues (pp. 259-286). Philadelphia, PA: Psychology Press.

Leon, J. A., \& Pepe, H. J. (1983). Self-instructional training: Cognitive behavior modification for remediating arithmetic deficits. Exceptional Children, 50, 54-60. Retrieved from http://connection.ebscohost.com/c /articles/19726289

Mastropieri, M. A. (1991). Mathematics instruction for learning disabled students: A review of research. Learning Disabilities Research and Practice, 6, 89-98.

Mastropieri, M. A., \& Scruggs, T. E. (1992). Science for students with disabilities. Review of Educational Research, 62, 377-411. Retrieved from http://www.jstor.org/stable/1170485 
Meyer, M. L., Salimpoor, V. N., Wu, S. S., Geary, D. C., \& Menon, V. (2009). Differential contribution of specific working memory components to mathematics achievement in 2nd and 3rd graders. Learning and Individual Differences, 20, 101-109. doi:10.1016/j.lindif/ 2009.08.004

Montague, M. (1992). The effects of cognitive and metacognitive strategy instruction on the mathematical problem solving of middle school students with learning disabilities. Journal of Learning Disabilities, $25,230-248$.

Montague, M. (1997). Cognitive strategy instruction in mathematics for students with learning disabilities. Journal of Learning Disabilities, 30, 164-177. doi:10.1177/0022219497030 00204

Montague, M. \& Dietz, S. (2009). Evaluating the evidence base for cognitive strategy instruction and mathematical problem solving. Council for Exceptional Children, 75, 285-302.

Montague, M., Enders, C., \& Dietz, S. (2011). Effects of cognitive strategy instruction on math problem solving of middle school students with learning disabilities. Learning Disability Quarterly, 34, 262 272. doi: $10.1177 / 0731948711421762$

National Mathematics Advisory Panel. (2008). Foundations for success: The final report of the National Mathematics Advisory Panel. Washington, DC: U.S. Department of Education. Retrieved from http://www2.ed.gov/about/bdscomm/list/mathpanel/report/final-report.pdf

National Research Council. (2002). Helping children learn mathematics (Mathematics Learning Study Committee, J. Kilpatrick \& J. Swafford, Eds., Center for Education, Division of Behavioral and Social Sciences and Education). Washington, DC: National Academy Press.

Pape, S. J., \& Smith, C. (2002). Self-regulating mathematics skills. Theory Into Practice, 41, 93-101. Retrieved from http://www.jstor.org/stable/1477460

Pegg, J., Graham, L., \& Bellert, A. (2005). The effect of improved automaticity of basic number skills on persistently low-achieving pupils. Proceedings of the 29th Conference of the International Group for the Psychology of Mathematics Education, 4, 49-56.

Rathvon, N. (2008). Effective school interventions: Evidence-based strategies for improving student outcomes. New York, NY: Guilford.

Resnick, L. B. (1982). Syntax and semantics in learning to subtract (Report No. LRDC- 198218). Pittsburgh, PA: Pittsburgh University, Learning Research and Development Center. (ERIC Document Reproduction Service, No. ED 221 386)

Russell, R. L., \& Ginsburg, H. P. (1984). Cognitive analysis of children's mathematical difficulties. Cognition and Instruction, 1, 217-244. Retrieved from http://www.jstor.org/stable/3233569

Saddler, B. (2006). Increasing story-writing ability through self-regulated strategy development: Effects on young writers with learning disabilities. Learning Disability Quarterly, 29, 291-305. Retrieved from http://www.jstor.org/stable/30035555

Scruggs, T. E., \& Mastropieri, M. A. (1990). Mnemonic instruction for learning disabled students: What it is and what it does. Learning Disability Quarterly, 13, 271-281. Retrieved from http://www.jstor.org/stable/1510353

Scruggs, T. E., \& Mastropieri, M. A. (2000). The effectiveness of mnemonic instruction for students with learning and behavior problems: An update and research synthesis. Journal of Behavioral Education, 10, 163-173. doi:10.1023/A:1016640214368

Steel, S. \& Funnell, E. (2001). Learning multiplication facts: A study of children taught by discovery methods in England. Journal of Experimental Child Psychology, 79, 37-55. doi:10.1006/jecp.2000.2579

Swanson, H. L. (2001). Research on interventions for adolescents with learning disabilities: A meta-analysis of outcomes related to higher-order processing. Elementary School Journal, 101, 330-347. Retrieved from http://www.jstor.org/stable/1002250 
Swanson, H. L., \& Jerman, O. (2006). Math disabilities: A selective meta-analysis of the literature. Review of Educational Research, 76, 249-274. doi:10.3102/00346543076002 249

Tournaki, N. (2003). The differential effects of teaching addition through strategy instruction versus drill and practice to students with and without learning disabilities. Journal of Learning Disabilities, 36, 449458. doi:10.1177/00222194030360050601

Vaughn, S., Bos, C. S., \& Weaver, T. L. (2012). Assessing and teaching mathematics. In S. Vaughn \& C. S. Bos (Eds.), Strategies for teaching students with learning and behavior problems (8th ed., pp. 366409). Upper Saddle River, NJ: Pearson Education, Inc.

Van de Walle, J. A. (2004). Elementary and Middle School Mathematics: Teaching Developmentally. Boston: Pearson Education, Inc.

Wolgemuth, J. R., Cobb, R. B., \& Alwell, M. (2008). The effects of mnemonic interventions on academic outcomes for youth with disabilities: A systematic review. Learning Disabilities Research \& Practice, 23, 1-10. doi:10.1111/j.1540-5826.2007.00258.x

Woodcock, R. W., McGrew, K. S., \& Mather, N. (2001). Woodcock-Johnson III. Itasca, IL: Riverside Publishing.

Woodward, J. (2006). Developing automaticity in multiplication facts: Integrating strategy instruction with timed practice drills. Learning Disability Quarterly, 29, 269-289. Retrieved from http://www.jstor.org/stable/30035554

\section{Authors' Note}

Correspondence concerning this article should be addressed to Matthew Waugh, Faculty of Education, University of Victoria, PO Box 1700, STN CSC, Victoria BC V8W 2Y2, Canada. Email: mwaugh86@uvic.ca 